\title{
Avaliação escolar: o olhar dos licenciandos sobre esse recurso didático
}

\author{
Andréia Francisco Afonso \\ Isabela Vieira da Silva \\ Vinícius da Silva Carvalho
}

\section{Resumo}

Avaliação escolar é um instrumento bastante utilizado pelos professores durante o ano letivo. Podemos até mesmo afirmar que é um recurso indispensável no contexto educacional. Acreditamos que ela pode trazer contribuições ao processo de ensino e de aprendizagem, ao proporcionar ao discente, momentos de reflexão sobre os conteúdos apresentados em sala de aula, no sentido de buscar estabelecer relações entre as diferentes áreas do conhecimento para uma apropriação mais ampla dos temas estudados. Também da prática docente, visando buscar soluções para os problemas apontados pelos resultados das avaliações, se caracterizando, portanto, como uma ferramenta de "diagnóstico e reorientação" e de mudanças. Nesse sentido, investigamos como cinco licenciandos em Química da Universidade Federal de Juiz de Fora planejaram seus instrumentos avaliativos, no sentido de investigar que elementos eles mobilizaram durante a elaboração dos mesmos. Os licenciandos demonstraram reconhecer a importância da prática avaliativa, pois indicaram objetivos, para os recursos avaliativos que criaram, que se voltaram a aprendizagem dos alunos. Apesar de duas licenciandas persistirem no modelo tradicional, houve a preocupação de inserir situações que são do cotidiano dos estudantes da Educação Básica, a fim de facilitar a associação dos conceitos químicos aos fenômenos que acontecem diariamente a nossa volta. Entretanto, consideramos que ainda é preciso um tempo maior para discussão e realização de atividades voltadas à temática avaliação escolar durante o processo de formação inicial. Ainda são poucos os espaços que os licenciandos encontram para o estudo do tema.

Palavras-chave: Avaliação escolar. Instrumentos avaliativos. Ensino Superior. Licenciatura em Química. 


\title{
SCHOOL EVALUATION: THE GRADUATES' LOOK AT THIS DIDATIC RESOURCE
}

\author{
Andréia Francisco Afonso \\ Isabela Vieira da Silva \\ Vinícius da Silva Carvalho
}

\section{Abstract}

School evaluation is an instrument widely used by teachers during the school year. We can even say that it is an indispensable resource in the educational context. We believe that it can contribute to the teaching and learning process by providing the student with moments of reflection about the contents presented in the classroom, in the sense of seeking to establish relationships between the different areas of knowledge for a broader appropriation of the themes studied. Also of the teaching practice, aiming to seek solutions to the problems pointed out by the results of the evaluations, being therefore characterized as a tool of "diagnosis and reorientation" and changes. In this sense, we investigated how five chemistry graduates of the Federal University of Juiz de Fora devised their evaluative instruments in order to investigate what elements they mobilized during their elaboration. The graduates demonstrated to recognize the importance of the evaluative practice, since they indicated objectives, for the evaluative resources that created, that they returned to the learning of the students. Although two graduates persisted in the traditional model, there was a concern to insert situations that are part of the daily life of Basic Education students, in order to facilitate the association of chemical concepts with the phenomena that happen around us daily. However, we believe that it is still necessary to spend more time discussing and carrying out activities related to school evaluation during the initial training process. There are still few spaces that the graduates find for the study of the subject.

Keywords: School evaluation. Evaluation instruments. Higher education. Chemistry graduation. 


\section{Introdução}

Avaliação escolar é um instrumento bastante utilizado pelos professores durante o ano letivo. Podemos até mesmo afirmar que é um recurso indispensável no contexto educacional. Muitas são as funções atribuídas a ela, porém, algumas não indicam uma preocupação com a aprendizagem dos estudantes, sendo feita apenas para obtenção de dados quantitativos - notas - as quais os docentes precisam atribuir ao "desempenho" de seus alunos: As notas escolares, como vêm sendo praticadas em nossas escolas, não nos ajudam a realizar o sonho, a esperança e o desejo da democratização do ensino. Ao contrário camuflam a realidade para que não enxerguemos os seus limitados processos e resultados (LUCKESI, 2014, p.17).

Por isso, acreditamos que os docentes realizam exames e não avaliações. Esses termos são utilizados como sinônimos, mas apresentam muitas diferenças, como mostra o Quadro 1:

Quadro 1: Diferenças entre avaliação e exame.

\begin{tabular}{|l|l|}
\hline \multicolumn{1}{|c|}{ AVALIAÇÃO } & \multicolumn{1}{c|}{ EXAME } \\
\hline Voltada para o futuro & Voltado para o passado \\
\hline Busca soluções para as dificuldades encontradas & Permanece aprisionado no problema \\
\hline Centrada no processo e no produto, ao mesmo tempo & Centrado no produto final \\
\hline Insere a complexidade & Simplifica a realidade \\
\hline Não é pontual & É pontual \\
\hline É diagnóstica: inclusiva, democrática, dialógica & $\begin{array}{l}\text { É classificatório: seletivo, } \\
\text { antidemocrático, autoritário. }\end{array}$ \\
\hline
\end{tabular}

Fonte: Adaptado de Luckesi, 2011.

São esses e outros aspectos que diferenciam avaliação e exame. Para Luckesi (2011), os exames são classificatórios, logo, excludentes por natureza, possuindo a finalidade de constatar o nível de desempenho do estudante em um determinado tempo fixado: "O passado é tomado como o tempo em que o estudante teve oportunidade de aprender; se não aprendeu, a responsabilidade é dele" (p. 193).

Os exames valorizam as notas dos estudantes que "são operadas e manipuladas como se nada tivessem a ver com o percurso ativo do processo de aprendizagem” (LUCKESI, 2009, p. 18), sem a intenção de refletir sobre os dados coletados ou agir a partir dos mesmos, de modo que possam promover intervenções que poderão contribuir com a aprendizagem.

O consenso no termo, ou seja, a determinação de uma definição única para avaliação escolar, ainda não foi alcançado. Há certa dificuldade em formar um conceito que seja aceito por todos os pesquisadores, devido à complexidade em torno deste tema, segundo os propósitos assumidos pela prática avaliativa. Entretanto, as pesquisas prosseguem voltadas a diferentes aspectos, especialmente, para as finalidades atribuídas a ela no contexto escolar. 
Mas para que a avaliação escolar auxilie no alcance dos objetivos indicados pela Base Nacional Comum Curricular (BNCC) para a Educação Básica, ela pode ser entendida como um recurso que possibilita a reflexão sobre o que se aprende e também se ensina, não ficando restrita ao ato de julgar o desempenho dos estudantes em um determinado momento pontual, "pois o professor que não avalia constantemente a ação educativa corre o risco de olhar apenas para os resultados baseado nos moldes e procedimentos da reprodução de informações" (UHMANN; ZANON, 2016, p.69).

Em uma avaliação pontual, esses resultados apenas terão a finalidade de indicar ao docente, aqueles estudantes que estão aptos a prosseguirem em uma etapa de escolarização mais avançada, seja no Ensino Fundamental, no Ensino Médio ou no Ensino Superior, ou até mesmo concluí-la. Contudo, se forem constatados problemas durante o percurso de construção do conhecimento, nenhuma ação é concebida e realizada.

As avaliações escolares realizadas nesse modelo são decorrentes da abordagem de ensino tradicional oferecida nas escolas ao longo das décadas. No ambiente escolar de ensino tradicional, os discentes são tidos como simples receptores de conhecimentos e os professores como transmissores, na conhecida “concepção 'bancária' da educação” (FREIRE, 2017, p. 80). Nesse modelo, a valorização da memorização e reprodução dos conceitos abordados em sala de aula é evidente.

Essa prática avaliativa era desenvolvida desde a época dos jesuítas, que foram os fundadores dos primeiros colégios no Brasil (NETO; MACIEL, 2008). Nestes colégios, os testes e exames eram os instrumentos mais comuns de avaliação (LUCKESI, 2009), uma vez que os estudantes eram avaliados de acordo com a capacidade de reprodução dos conhecimentos. $\mathrm{E}$ de acordo com os resultados, eles eram classificados pelos professores em "ótimos, bons, medíocres, duvidosos, insuficientes (para repetir o ano)" (FRANCA, 1952, p. 77).

Embora, atualmente, a abordagem tradicional persista em algumas salas de aula, sabemos que alguns docentes estão buscando uma prática que se volte ao diálogo, tornando o aluno, um protagonista de sua própria aprendizagem. Nessa perspectiva, Silva e Moradillo (2002, p.34) definem um outro papel para a avaliação escolar:

[...] na concepção dialética a avaliação vai se voltar para a dinâmica da criação, pois os alunos são vistos como participantes ativos do processo de aprendizagem. De coadjuvantes de um processo de conhecimento que tende a se esgotar naqueles ensinamentos, os estudantes passam a atores e autores do aprender a aprender, avançando através do exercício da crítica e da avaliação.

Entretanto, acreditamos que a avaliação escolar pode ir além nas suas contribuições, ao proporcionar ao discente, momentos de reflexão sobre os conteúdos apresentados em sala de aula, no sentido de buscar estabelecer relações entre as diferentes áreas do conhecimento 
para uma apropriação mais ampla dos temas estudados, se caracterizando, portanto, como uma ferramenta de "diagnóstico e reorientação" (LEMOS; SÁ, 2013, p.54) e de mudanças (LUCKESI, 2009).

A BNCC aponta como uma das competências a serem desenvolvida na Educação Básica, essa interação, no sentido de

4. Utilizar diferentes linguagens - verbal (oral ou visual-motora, como Libras, e escrita), corporal, visual, sonora e digital -, bem como conhecimentos das linguagens artística, matemática e científica, para se expressar e partilhar informações, experiências, ideias e sentimentos em diferentes contextos e produzir sentidos que levem ao entendimento mútuo (BRAIL, 2018, p.9).

Hoffmann (2011a) também compartilha essa concepção, quando afirma que "a avaliação deixa de ser um momento terminal do processo educativo (como hoje é concebida) para se transformar na busca incessante de compreensão das dificuldades do educando e na dinamização de novas oportunidades de conhecimento" (p.19), "num acompanhamento permanente do professor, que incitará o aluno a novas questões a partir de respostas formuladas" (p.18).

A BNCC, ao se referir a avaliação, indica que uma das ações da comunidade escolar deve ser:

Construir e aplicar procedimentos de avaliação formativa de processo ou de resultado que levem em conta os contextos e as condições de aprendizagem, tomando tais registros como referência para melhorar o desempenho da escola, dos professores e dos alunos (BRASIL, 2018, p.17).

Lamas (2005, apud RAMOS; MORAES, 2010, p.321) vai além:

[...] avaliação tem o propósito de informar sobre os acertos, estimular a comunicação, facilitar a formação, potencializar a participação, promover a autoestima, oferecer recomendações, garantir as mesmas possibilidades a todos e contribuir para a aprendizagem docente. Por outro lado, destaca que a avaliação não tem o propósito de originar queixas e protestos, gerar conflitos entre pessoas, favorecer o desânimo, ser um fim em si mesma, fomentar a competitividade, promover abandonos, repudiar o erro, selecionar, punir, excluir.

Um dos motivos para que a prática da simples verificação ou a simples aplicação de exames, ao invés da avaliação, persista nas salas de aula, se deve ao fato do pouco espaço despendido à discussões a respeito da avaliação escolar ao longo do curso de formação inicial de professores (BARBOSA, 2011; BOAS, SOARES, 2016; HOFFMANN, 2011b; PERRENOUD, 1999).

Segundo Perrenoud (1999), esse assunto é pouco abordado durante a formação inicial ISSN 2526-2882 
e menos ainda em relação as formas de torná-la uma ferramenta auxiliar no processo de ensino e aprendizagem. Logo, para Hoffmann (2011b), existe uma "superficialidade de formação da maioria dos professores nessa área” (p.148). Ainda segundo ela, muitos professores atuantes nas escolas de Educação Básica nunca foram instigados a uma análise teórica sobre a avaliação escolar.

Na Universidade Federal de Juiz de Fora (UFJF), há uma disciplina obrigatória para os licenciandos em Química, intitulada Planejamento e Avaliação do Ensino de Química”. Ela é um dos componentes que integram na matriz do nono período do curso de Licenciatura em Química. Além dessa disciplina, outra - Instrumentação para o Ensino de Química - do sétimo período do curso, também tem entre seus conteúdos, discussões sobre os instrumentos avaliativos que podem ser elaborados e utilizados pelos futuros professores.

Diante do contexto apresentado, este artigo apresenta uma análise dos instrumentos avaliativos, propostos por licenciandos em Química da UFJF, durante a disciplina Instrumentação para o Ensino de Química, ministrada por uma das autoras deste trabalho.

\section{Procedimento metodológico}

Este estudo pode ser classificado como qualitativo, pois nas pesquisas com essa abordagem "é frequente que o pesquisador procure entender os fenômenos, segunda a perspectiva dos participantes da situação estudada e, a partir, daí situe sua interpretação dos fenômenos estudados" (NEVES, 1996, p.1).

A disciplina de Instrumentação para o Ensino de Química é ofertada aos licenciandos do curso de Química Diurno e Noturno da UFJF. Ela integra a matriz curricular do sétimo período e é de responsabilidade do Departamento de Química. Contudo, para cursá-la, o licenciando deve ter sido aprovado em Metodologia do Ensino de Química, disciplina do quarto período. Ela tem duração de quatro horas semanais, distribuída em dois dias, contabilizando ao final, 60 horas/créditos.

As demais disciplinas, voltadas para a área de Educação, que também integram a matriz curricular, e que antecedem a Instrumentação para o Ensino de Química, estão indicadas no Quadro 2:

Quadro 2: Disciplinas com abordagem pedagógica que integram a matriz curricular dos cursos de Química - Noturno e Diurno. 


\begin{tabular}{|c|c|c|c|}
\hline DISCIPLINA & PERÍODO & PRÉ-REQUISITO & LOCAL \\
\hline Introdução à Educação Química & $1^{\mathrm{o}}$ & Não há & $\begin{array}{l}\text { Departamento } \\
\text { de Química }\end{array}$ \\
\hline História da Química & $3^{0}$ & Não há & $\begin{array}{l}\text { Departamento } \\
\text { de Química }\end{array}$ \\
\hline Saberes Químicos Escolares & $3^{\mathrm{o}}$ & Não há & $\begin{array}{l}\text { Faculdade de } \\
\text { Educação }\end{array}$ \\
\hline $\begin{array}{l}\text { Prática Escolar em } \\
\text { Químicos Escolares }\end{array}$ & $3^{o}$ & Não há & $\begin{array}{l}\text { Faculdade de } \\
\text { Educação }\end{array}$ \\
\hline $\begin{array}{l}\text { Políticas Públicas e Gestão do } \\
\text { Espaço Escolar }\end{array}$ & $4^{\circ}$ & Não há & $\begin{array}{l}\text { Faculdade de } \\
\text { Educação }\end{array}$ \\
\hline $\begin{array}{l}\text { Prática Escolar em } \text { Políticas } \\
\text { Públicas }\end{array}$ & 40 & Não há & $\begin{array}{l}\text { Faculdade de } \\
\text { Educação }\end{array}$ \\
\hline $\begin{array}{lll}\begin{array}{l}\text { Processo de } \\
\text { Aprendizagem }\end{array} & \text { Ensino } & \mathrm{e}\end{array}$ & 50 & Não há & $\begin{array}{l}\text { Faculdade de } \\
\text { Educação }\end{array}$ \\
\hline $\begin{array}{l}\text { Ensino de Química na Escola } \\
\text { Básica I }\end{array}$ & 50 & Metodologia de Ensino & $\begin{array}{l}\text { Faculdade de } \\
\text { Educação }\end{array}$ \\
\hline $\begin{array}{l}\text { Prática em Ensino de Química na } \\
\text { Escola Básica I }\end{array}$ & 50 & Metodologia de Ensino & $\begin{array}{l}\text { Faculdade de } \\
\text { Educação }\end{array}$ \\
\hline $\begin{array}{l}\text { Ensino de Química na Escola } \\
\text { Básica II }\end{array}$ & $6^{0}$ & $\begin{array}{l}\text { Ensino de Química na Escola Básica I } \\
\text { Prática em Ensino de Química na Escola } \\
\text { Básica I } \\
\text { Química Inorgânica } \\
\text { Termodinâmica e Cinética }\end{array}$ & $\begin{array}{l}\text { Faculdade de } \\
\text { Educação }\end{array}$ \\
\hline
\end{tabular}

Fonte: Os autores

Assim, ao chegarem na disciplina de Instrumentação para o Ensino de Química, os licenciandos já tiveram contato com referenciais teóricos da área de Educação, de forma mais ampla, e de Educação Química. Também participaram de discussões sobre diferentes assuntos associados ao contexto educacional. Inclusive, tiveram oportunidade de ter um contato mais próximo com a realidade escolar, inserindo-se nas instituições de Educação Básica, por meio das disciplinas de práticas. Estas informações são importantes, pois acreditamos que, ao longo do percurso formativo, o licenciando (re)constrói suas concepções, especialmente aquelas relacionadas ao ser professor.

Os dados apresentados neste trabalho se baseiam na disciplina Instrumentação para o Ensino de Química, que foi ofertada no segundo semestre de 2018 e contou com a participação de seis licenciandos em Química. As aulas ficaram sob a reponsabilidade de uma das autoras, professora do Departamento de Química da UFJF, mas foram ministradas em parceria com os outros dois autores desse trabalho, pós-graduandos do Programa de PósGraduação em Química da mesma Universidade. Elas aconteceram às terças-feira, das 19 às 21 horas e às quartas-feira, das 21 às 23 horas.

A ementa da disciplina, assim como o conteúdo da disciplina estão descritos a 
seguir $^{29}$ :

Ementa: Estudo sistemático dos documentos oficiais voltados ao ensino de Química na Educação Básica, bem como avaliação e aplicação dos mesmos em propostas de Ensino Aprendizagem. Elaboração de propostas de ensino com base nas principais tendências e conhecimentos da área de Educação Química com ênfase nos níveis de conhecimento e na natureza do conhecimento químico. Avaliação de material didático e preparação de aulas para alunos do Ensino Médio.

Conteúdos: Tendências do ensino de ciências. Documentos oficiais voltados ao ensino de Química na Educação Básica. Aprendizagem significativa e mapas conceituais. Os Níveis de pensamento macroscópico, simbólico, submicroscópico. A natureza do conhecimento científico e o papel dos modelos no ensino de ciências. Avaliação de livros didáticos. Ensino de Química no Ensino Fundamental. Propostas alternativas para o ensino de química: Materiais didáticos, Paradidáticos e Novas tecnologias para o ensino. Fontes de informação para o professor de química. Elaboração de uma ferramenta para avaliação de aula. Preparação de aula para estudantes do Ensino Médio. Linguagem e mediação no ensino de ciências

Pela descrição da ementa e dos conteúdos, podemos perceber que há um tópico que possibilita a abordagem de avaliação escolar (grifado). Assim, em duas aulas, promovemos uma discussão sobre avaliação educacional: a de larga escala e a escolar. Para a abordagem da avaliação em larga escala, apresentamos slides com definições, finalidades e exemplos das mesmas. Fizemos também uma análise pedagógica de um dos itens do Exame Nacional do Ensino Médio, discutindo os critérios para classificá-lo com bom ou regular. Caso os licenciandos julgassem que era preciso propor alterações no referido item, eles deveriam apontar quais e em que parte - no enunciado, no comando e/ou nas alternativas.

Para a aula sobre avaliação escolar, discutimos um texto que aborda a diferença entre verificação e avaliação (LUCKESI, 2009) e um outro que faz alusão a diferenciação entre avaliação e exame (LUCKESI, 2011). Estes textos foram enviados por correio eletrônico aos licenciandos, uma semana antes da data da referida.

Em seguida, em uma terceira aula, propomos aos licenciandos a realização da atividade que consistia na elaboração de um instrumento avaliativo, com a condição de ser inédito. Na elaboração, eles deveriam considerar as discussões realizadas até o momento, assim como outras produções entregues em aulas anteriores. Eles puderam consultar livros, a internet e outros materiais.

${ }^{29}$ Disponível em http://www.ufjf.br/quimica/disciplinasdep/plano-de-ensino/?CodDisciplina=QUI146 Acesso em 28 de fevereiro de 2019. ISSN 2526-2882 
$\mathrm{Na}$ última aula da disciplina, no mês de novembro de 2018, dos seis licenciandos, cinco $^{30}$ apresentaram e entregaram à professora suas avaliações escolares. Cada um deles expôs ao grupo suas concepções sobre educação e ensino, adquiridas ao longo do semestre e da sua trajetória acadêmica, suas impressões sobre avaliação e suas características, enquanto futuros docentes. Elas os ajudaram a optar pelo instrumento avaliativo a ser elaborado.

Os instrumentos avaliativos fazem parte dos dados que compõem este estudo, assim como o registro no diário de campo dos autores, das observações e relato dos licenciandos durante as apresentações. Eles foram interpretados por meio da Análise de Conteúdo, que segundo Bardin (2016), pode ser compreendida como "um conjunto de instrumentos metodológicos cada vez mais sutis e constante aperfeiçoamento, que se aplicam a "discursos" (conteúdos e continentes) extremamente diversificados" (p.15).

Para isso, criamos categorias que nos ajudaram a interpretar os dados. Essas categorias foram construídas a posteriori, a partir de unidades de registro retiradas dos diários de campo dos autores e dos instrumentos avaliativos entregues pelos licenciandos.

\section{Resultados e Discussão}

De acordo com os instrumentos avaliativos apresentados, pudemos identificar que duas das cinco produções foram elaboradas segundo o modelo tradicional, de prova. As questões, muitas vezes, exigiam a memorização de conceitos para que o (suposto) aluno pudesse respondê-la, como mostra trechos das avaliações a seguir:

Com relação a mudança desses estados físicos, o que você entende por:

a) Fusão:

b) Solidificação:

c) Vaporização:

d) Ebulição:

(Questão 1 do instrumento avaliativo da licencianda Roberta)

O que é solubilidade? Dê um exemplo.

O que é polaridade?

(Questões 1 e 2 do instrumento avaliativo de Olga).

Roberta acredita que com sua "prova”, ela poderia ajudar os estudantes a construírem o conceito de termos tão utilizados pela Química. Segundo a licencianda: "Acho muito

$3^{30}$ Nesse trabalho, eles serão identificados por Aline, Guilherme, Maria, Olga e Roberta para preservar a identidade dos licenciandos.

ISSN 2526-2882 
importante o conceito estar bem claro no pensamento deles, para a partir daí, por exemplo, fazer intepretação de gráficos e tabelas”. Essa resposta, que foi redigida na mesma folha do instrumento avaliativo entregue a professora, pode ter sofrido influência da leitura das Orientações Educacionais Complementares aos Parâmetros Curriculares Nacionais (PCN+), realizada pela licencianda e apresentados em slides, na forma de seminário no mês de agosto, como uma outra atividade da disciplina. Segundo os PCN+, duas das competências da Química são

\begin{abstract}
Ler e interpretar informações e dados apresentados com diferentes linguagens ou formas de representação, - como símbolos, fórmulas e equações químicas, tabelas, gráficos, esquemas, equações.

Selecionar e fazer uso apropriado de diferentes linguagens e formas de representação, como esquemas, diagramas, tabelas, gráfico, traduzindo umas nas outras. Por exemplo, traduzir em gráficos informações de tabelas ou textos sobre índices de poluição atmosférica em diferentes períodos ou locais (BRASIL, 2007, p.89).
\end{abstract}

Já Olga, que em um momento anterior na disciplina, no mês de outubro, apresentou uma aula simulando estar em laboratório realizando experimentos, justificou a elaboração do seu recurso como sendo a única forma de avaliar os conhecimentos apresentados durante o desenvolvimento das atividades práticas.

Entretanto, Olga criou uma questão envolvendo substâncias conhecidas pelos alunos, de modo a "avaliar a visualização no cotidiano". Ela a denominou de "questão bônus", ou seja, uma questão opcional, que o aluno responde somente se tem dificuldade nas anteriores.

Questão bônus: Diga se os componentes abaixo são solúveis ou não. Justifique:

a) Sal de cozinha $(\mathrm{NaCl})+$ água:

b) Água +óleo:

c) Água +óleo + sabão:

d) Àlcool $+\mathrm{NaCl}$ :

e) Álcool +água:

f) Dê 3 exemplos de substâncias do seu cotidiano que se solubilizam umas nas outras:

(Questão bônus do instrumento avaliativo de Olga).

Vale destacar que as misturas, indicadas nas letras de A a E da questão bônus, foram utilizadas nas atividades experimentais na aula de Olga. No trabalho de Rocha e Sá (2019, p.74), há um apontamento das professoras, participantes da referida pesquisa, da importância da abordagem de situações do cotidiano. 
[...] as três professoras apresentarem concepções adequadas acerca do ensino, tais como aquelas relacionadas à valorização dos conhecimentos prévios dos estudantes, a importância da experimentação, a abordagem de situações do cotidiano e a necessidade de melhor formação para lidar com as novas tecnologias.

Já Guilherme pensou em situações-problema a serem solucionadas pelos estudantes, em grupos.

Problema 1: 20 anos se passaram desde a implementação do parque. Atualmente, o número de visitantes aumentou bastante, e com isso, a produção de lixo. Diversos funcionários prestaram reclamações à direção do parque, devido à grande quantidade de lixo recolhida diariamente, principalmente, em locais indevidos. Pesquise os possíveis tipos de lixo que seriam mais encontrados nessa região. Quais os problemas que o acúmulo desse lixo pode gerar na sobrevivência da fauna e da flora? Proponha três maneiras de resolver este problema. Seja criativo!

Problema 2: Após 20 anos, o efeito da implementação do parque já pode ser observado. Um grupo de pesquisadores da região, ao analisar a água do rio, determinou uma grande concentração de metais. Pesquise sobre o efeito que uma grande concentração de íons metálicos pode ocasionar na água do parque. Escolha três metais, dentre os que já foram estudados durante o ano letivo, e comente sobre seu uso, aplicações e riscos à saúde dos seres humanos. Por que o monitoramento das substâncias químicas em rios e lagos é importante? Problema 3: 20 anos após a implementação do parque, alguns problemas começaram a aparecer. Um grupo de pesquisadores da região, ao analisarem amostras do solo, perceberam que o $\mathrm{pH}$ estava fora do esperado para a região. Pesquise o que poderia estar causando esse problema, assim como a importância do monitoramento do $\mathrm{pH}$ do solo. Proponha uma forma de reverter essa situação.

(Questões-problema elaboradas por Guilherme).

De acordo com De Lima e Weber (2019, P.70),

Neste tipo de atividade, $o$ aluno tem a oportunidade de interagir com a ciência da maneira esperada para um indivíduo cientificamente letrado: após despertada a curiosidade, ele irá observar, classificar, discutir o problema, aplicando conhecimentos científicos, relatar a resolução do problema e apresentar uma solução utilizando a linguagem científica, na modalidade escrita ou oral, argumentar e julgar os resultados obtidos, confrontando-os com a literatura científica.

Em sua aula, Guilherme simulou um júri, no qual a questão a ser discutida foi a criação de um parque, envolvendo questões ambientais e de comércio nas proximidades. Na ISSN 2526-2882 
atividade, a professora e os colegas representaram funcionários da Prefeitura, do Instituto Brasileiro do Meio Ambiente e dos Recursos Naturais Renováveis (IBAMA), da associação de moradores do local e dos comerciantes e pesquisadores de uma instituição de ensino superior.

Todos os presentes, ao final de apresentação da proposta, apontaram sugestões, de modo a tornar a aula mais adequada à realidade de sala de aula. Uma das sugestões foi o tempo de aplicação - número de aulas -, uma vez que para construírem seus argumentos, os estudantes da Educação Básica precisam de tempo para pesquisarem e redigirem seus textos. Além disso, que os argumentos a serem redigidos pelos alunos tivessem um direcionamento para que os conteúdos químicos estudados fossem inseridos. Na proposta apresentada, os argumentos poderiam ser construídos a partir da opinião individual, sem qualquer aporte científico.

Com seu instrumento avaliativo, Guilherme retoma o júri simulado, e relata que com ele conseguiria superar algumas das lacunas identificadas em sua aula. Ele foi o único a apontar mais de um objetivo para o instrumento avaliativo elaborado. São eles:

Introduzir os alunos no processo de pesquisa.

Trabalhar a oratória, a argumentação e o senso crítico.

Se posicionar frente a uma questão política, social e econômica.

Relacionar o conteúdo de Química com questões ambientais.

Trabalhar em grupo e criar empatia.

O processo de avaliação, planejado por Guilherme, foi dividido em duas partes: o registro no diário de campo pelos alunos durante a construção dos argumentos, que teria cinco pontos, como o máximo a ser atingido; e a participação no júri simulado, dez pontos. Essas atividades comporiam a nota bimestral do estudante.

Aline pensou em um modelo de avaliação diferente: a roda de conversa (Figura 1). Seus objetivos eram saber se os alunos compreenderam os conceitos de modelo atômico; se conseguiriam distinguir os modelos atômicos estudados e identificar os modelos através das representações por imagens.

Os colegas de Aline a questionaram sobre como ela conseguiria obter os resultados, uma vez que na roda de conversa, podemos ter alunos que se expressam com muita facilidade e aqueles mais tímidos, que apesar de terem aprendido os conteúdos, não os verbalizam, devido a timidez. Ela alegou que ficaria mais perto dos alunos, estimulando-os a falarem. Entretanto, parece que a resposta não convenceu os colegas da disciplina, que pela continuação dos questionamentos, pareceram não terem se convencido da eficácia do instrumento criado pela licencianda. 
Maria, que já leciona em um curso preparatório para o ENEM e outros concursos, oferecido pela Prefeitura de Juiz de Fora (MG), relatou durante algumas aulas da disciplina, sua preocupação com a dificuldade de leitura e, consequentemente, interpretação dos textos e enunciados das atividades e das provas aplicadas por ela. Assim, seu instrumento avaliativo foi um texto, cujo título era: "Sal tem a propriedade de derreter os cristais de gelo". Esse texto foi retirado do sítio Folha Teen, publicado no dia 18 de abril de 1994. A preocupação da licencianda com a leitura via ao encontro do estudo de Silva (1997, p.147):

[...] ao pensar a leitura no ensino de física é importante não apenas pensar no como fazer para os alunos compreenderem os textos, mas também no como fazer para que eles queiram compreender os textos. Não apenas no como fazer para que os alunos leiam os textos, mas também no como fazer para que os alunos queiram ler sobre ciência, sobre física.

Francisco Junior (2011, p.161) acredita que "cabe ao professor de ciências também prover oportunidades para que os alunos exerçam a escrita e a leitura em sala de aula. Isso porque todas as disciplinas escolares são suportadas na linguagem escrita”. A licenciada faria algumas perguntas sobre o texto, buscando relacionar ao cotidiano dos alunos, pois, segundo ela, as pessoas colocam sal sobre o gelo para manter as bebidas geladas por mais tempo, mas não sabem explicar cientificamente o fenômeno.

Instrumento avaliativo de Aline: Mesa redonda: A evolução dos modleos atômicos A proposta da atividade é criar um msa redonda para que os alunos possam discutir sobre a evoluçao dos modelos atômicos.

A discussão não seguiria uma odem cronológica, pois o interessante é observar o que os alunos lembram sobre cada um dos modelos, e se os mesmos conseguem faer a distinção dos mesmos. Desa forma, os temas seriam sorteados aleatoriamente. Primeiramente os alinos se dividiriam em grupos e sorteariam um tema referente a um dos modelos atômicos e teriam um tempo para discussão. Depois o grupo nomearia um representante para integrar a mesa e discutir sobre o tema sorteado. O professor deverá agir como mediador, preenchando as lacunas e incentivando os alunos a argumentar.

Assim o representante deverá começar a discussão, e a pedido do professor o próximo membro do grupo deverá continuar o raciocínio. Caberão aos demais alunos então die por que este modelo não é adequado. Ao final da discussão então será solicitado que os alunos identifiquem quais figuras correspondem a cada um dos modelos e coloquem os mesmos em ordem cronológica de sau evolução. Opçõs para serem sorteados pelos alunos:

1-Esfera maciça

2-Pudim de passas 
3-Sistema solar

4-Modelo quântico

imagens para identificação dos modelos
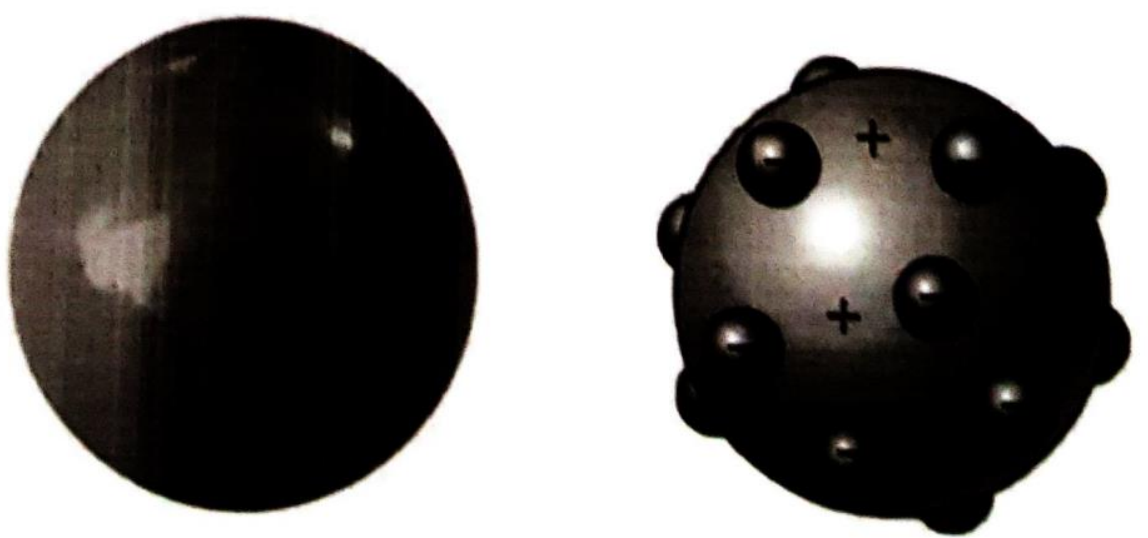

Figura 1: Instrumento avaliativo de Aline.

\section{Considerações Finais}

Os licenciandos demonstraram mobilizar os conhecimentos da área de Educação, adquiridos até o momento de cursarem a disciplina Instrumentação para o Ensino de Química. Apesar de duas licenciandas persistirem no modelo tradicional, houve a preocupação de inserir situações que são do cotidiano dos estudantes da Educação Básica, a fim de facilitar a associação dos conceitos químicos aos fenômenos que acontecem diariamente a nossa volta.

Entretanto, consideramos que ainda é preciso um tempo maior para discussão e realização de atividades voltadas à temática avaliação escolar durante o processo de formação inicial. Ainda são poucos os espaços que os licenciandos encontram para o estudo do tema.

Enquanto isso, prática avaliativas, apoiadas nos exames, vão se mantendo e reproduzindo-se ao longo dos tempos no contexto educacional, não fornecendo indícios de que é preciso uma reflexão e modificação de alguns fatores que estão comprometendo o processo de ensino e de aprendizagem.

Acreditamos que se houverem mais oportunidades como essa, os licenciandos poderão rever as práticas avaliativas que vêm sendo desenvolvidas, baseadas na memorização dos alunos, buscando instrumentos e metodologias, que os ajudem a construir um processo de ensino e aprendizagem com qualidade. 


\section{Referências}

BARBOSA, F. R. P. Avaliação da aprendizagem na formação de professores: teoria e prática em questão. Dissertação (Mestrado em Educação) - Programa de PósGraduação em Educação, Universidade Federal do Rio Grande do Sul, Porto Alegre, 2011.

BARDIN, L. Análise de conteúdo. São Paulo: Edições 70, 2016.

BOAS, B. M. F. V.; SOARES, S. L. O lugar da avaliação nos espaços de formação de professores. Cadernos Cedes, Campinas, v. 36, n. 99, p. 239-254, 2016.

BRASIL. Ministério da Educação. Base Nacional Comum Curricular. Brasília, DF: MEC/CNE, 2018.

. Ministério da Educação. Orientações Educacionais Complementares aos Parâmetros Curriculares Nacionais (PCN+). Brasília, DF: MEC/CNE, 2007.

DE LIMA, M. S.; WEBER, K. C. Determinação de níveis de letramento científico a partir da resolução de casos investigativos envolvendo questões sociocientíficas. Edicación Química, v.30, n.1. p.69-79, 2019.

FRANCA, L. O método pedagógico dos jesuítas: o "Ratio Studiorum”. Rio de Janeiro: AGIR, 1952. Disponível em: < https://portalconservador.com/livros/PeLeonel\%20Franca-O-Metodo-Pedagogico-dos-Jesuitas.pdf >. Acesso em: o7 nov. 2018.

FRANCISCO JUNIOR, W. E. Analisando uma estratégia de leitura baseada na elaboração de perguntas e de perguntas com respostas. Investigações em Ensino de Ciências, v.16(1), pp. 161-175, 2011.

FREIRE, P. Pedagogia do oprimido. 64. ed. Rio de Janeiro/ São Paulo: Paz e Terra, 2017.

HOFFMANN, J. Avaliação mediadora: uma prática em construção da pré-escola à universidade. 31. ed. Porto Alegre: Mediação, 2011b.

J. Avaliação, mitos e desafios: uma perspectiva construtivista. 41. ed. Porto Alegre: Mediação, 2011a.

LEMOS, P. S.; SÁ, L. P. A avaliação da aprendizagem na concepção de professores de química do ensino médio. Revista Ensaio, Belo Horizonte, v.15, n.3, p. 53-71. Set-dez, 2013.

LUCKESI, C. C. Avaliação da aprendizagem como componente do ato pedagógico.

São Paulo: Cortez, 2011.

, C. C. Avaliação da aprendizagem escolar: estudos e preposições. 20. ed. São Paulo: Cortez, 2009.

, C. C. Sobre notas escolares: distorções e possibilidades. São Paulo: Cortez, 2014.

NETO, A. S.; MACIEL, L. S. B. O ensino jesuítico no período colonial brasileiro: algumas discussões. Educar em revista, Curitiba, n. 31, p. 169-189, 2008. 
NEVES, J. L. Pesquisa qualitativa - pesquisas, usos e possibilidades. Cadernos de Pesquisa em Administração, v.1, n.3, p.1-5, 1996.

PERRENOUD, P. Avaliação: da excelência à regulação das aprendizagens - entre duas lógicas. Tradução de Patrícia C. Ramos. Porto Alegre: Artmed, 1999.

RAMOS, M. G.; MORAES, R. A avaliação em Química: Contribuição aos processos de mediação da aprendizagem e de melhoria do ensino. In: SANTOS, Wildson Luiz P.; MALDANER, Otávio Aloisio. (Org.). Ensino de Química em Foco. 1. ed. Ijui: Editora Unijui, 2010, v.1, p. 313-330.

ROCHA, R. N.; SÁ, L. P. Trajetórias de vida e desenvolvimento profissional docente de professores de química. Revista Electrónica de Enseñanza de las Ciencias, v. 18, n.1, p.56-78, 2019.

SILVA, H. C. da. Como, quando e o que se lê em aulas de física no ensino médio: elementos para uma proposta de mudança. Dissertação (Mestrado em Educação) Programa de Pós-Graduação em Educação, Universidade Estadual de Campinas, Campinas, 1997.

SILVA, J. L. P. B.; MORADILLO, E. F. Avaliação, ensino e aprendizagem de ciências. Revista Ensaio, Belo Horizonte, v.4, n.1, p.28-39. Julho, 2002.

UHMANN, R. I. M.; ZANON, L. B. Avaliação escolar em discussão no processo constitutivo da docência. Debates em Ensino de Química, v.2, n.1, Abr., p.66-72, 2016.

\section{Biografia Resumida}

Isabela Vieira da Silva: Licenciada em Química e Bacharela em Ciências Exatas pela Universidade Federal de Juiz de Fora UFJF; Mestranda em Química, área de concentração: Educação em Química pela UFJF; Integrante do Grupo De Estudos em Educação Química (GEEDUQ/ UFJF).

Link do lattes: http://lattes.cnpq.br/7422295926724865

Contato: isabelavdsilva@gmail.com

Andréia Francisco Afonso: Licenciada em Química pela Universidade de Uberaba e em Ciências Biológicas pela Universidade do Estado do Rio de Janeiro; Mestrado em Ciências Biológicas (Área de concentração Zoologia) pelo Museu Nacional do Rio de Janeiro e Doutorado em Ciências (Área de concentração Química) pela Universidade Federal de São Carlos; 
Atualmente é Professora Adjunta do Departamento de Química, no Programa de Pós-Graduação em Química e no curso de Especialização em Ensino de Ciências e Matemática nos anos iniciais da Universidade Federal de Juiz de Fora; Especialista da área de Ciências da Natureza do CAED/UFJF (Centro de Políticas Públicas e Avaliação da Educação) e coordenadora do subprojeto Química PIBID-UFJF.

Link do lattes: http://lattes.cnpq.br/1105432487453207

Contato: andreia.afonso@ufjf.edu.br

Vinícius da Silva Carvalho: Licenciado em Química Universidade Federal de Juiz de Fora - UFJF; Técnico em Química pelo Centro Educacional Conceição Ferreira Nunes (CECON); possui especialização em Libras e Educação para Surdos pela Universidade Norte do Paraná; Mestre em Química, área de concentração: Educação em Química pela UFJF. Doutorando em educação química pela UFJF. Analista de Instrumentos de Avaliação III da área de Ciências da Natureza do CAED/UFJF (Centro de Políticas Públicas e Avaliação da Educação).

Link do lattes: http://lattes.cnpq.br/7253947858736806

Contato: vinicius.scq@gmail.com 